\title{
Surface Modifications of the Biodegradable Magnesium Based Implants with Self-Assembled Monolayers Formed by T-BAG Method
}

\author{
Ivana Škugor Rončević, Nives Vladislavić and Marijo Buzuk \\ Department of General and Inorganic Chemistry, Faculty of Chemistry and Technology, University of Split, \\ R. Boškovića 35, 21000 Split, Croatia \\ * Corresponding author: E-mail: skugor@ktf-split.hr \\ Tel.: +385-213-29472; Mobile: +385-987-09455
}

Received: 13-04-2018

Surface modifications with SAM formed T-BAG method

\begin{abstract}
In this paper, magnesium based materials (Mg and Mg-alloy (AZ91D)) were surface modified using various organic acids (carboxylic and phosphonic), in order to improve corrosion resistance and enhance theirs biocompatibility. Formations of surface layer were performed by tethering by aggregation and growth (T-BAG) method. Organization and bond mode of these layers were examined by Fourier transform infrared spectroscopy (FTIR). Additionally, semiempirical quantum molecular modeling calculation methods were used for getting insight into their structural and electronic properties, as also as corrosion resistance in the physiological solution (Hanks' solution). Corrosion resistance of modified materials were investigated by electrochemical impedance spectroscopy (EIS) in the physiological solution (Hanks' solution) and obtained results reveal a beneficial effect of the modification by forming organic acids self-assembled monolayer (SAM) on the corrosion properties of magnesium based materials, especially layers of octadecylphosphonic acid. The maximum corrosion inhibition efficiency of $87 \%$ for magnesium and of $93 \%$ for Mg-alloy (AZ91D) are achieved by the formation of octadecylphosphonic acid (ODPA) SAM.
\end{abstract}

Keywords: Magnesium based materials; electrochemical impedance spectroscopy (EIS); self-assembling monolayer (SAM); tethering by aggregation and growth (T-BAG).

\section{Introduction}

Biodegradability and similar mechanical properties to human bone make magnesium and its alloys a promising candidate for implantable materials used in medical devices. ${ }^{1}$ As a potential biodegradable material, magnesium shows many advantages over current metallic materials and biodegradable plastics and ceramics. Therefore, $\mathrm{Mg}$ and its alloys have been successfully applied as scaffolds, load bearing and biodegradable orthopedic implants in the physiological environment. Considerable literature is available on the corrosion behavior and electrochemical properties of magnesium and its alloys and Xiaodong et al. have published an excellent article on microstructure and bio-corrosion behavior of as-cast $\mathrm{Mg}-2 \mathrm{Zn}-0.5 \mathrm{Ca}-\mathrm{Y}$ series alloys for biomedical application. ${ }^{2}$ Several $\mathrm{Mg}$ alloys, such as Mg-Al-Zn, Mg-Al-Mn, LAE442, Al-free WE43, Mg-Zn and $\mathrm{Mg}-\mathrm{Ca}$, were investigated and developed as biodegrad- able metallic materials. ${ }^{3}$ Nevertheless, several problems such as inadequate strength when used at load-bearing sites, rapid corrosion characterized by hydrogen evolution must be solved before using this metal in biomedical purposes. ${ }^{4}$ In the human body, these hydrogen bubbles can be accumulated in gas pockets next to the magnesium based implant and can slow tissue recovery or even cause necrosis of tissue. ${ }^{5}$ For improving the lifetime of Mg alloys, their surface can be modified by introducing various organic coatings. Different chemical treatments, such as deposition of chemical conversion layers, ${ }^{6}$ treatments based on the sol-gel application ${ }^{7}$ and the surface modification by formation of self-assembling monolayers (SAMs) of non-toxic organic molecules on the native oxide surfaces by a simple immersion process, were used. ${ }^{8,9}$ As one of the important factor enhancing corrosion resistance (thus improving durability and performability) of implantable materials, is adhesion of organic coatings on implantate surface. ${ }^{10}$ 
In a corrosion system containing the aggressive anions and the inhibitor anions, oxidized metal acts as a hard Lewis acid and anions act as Lewis bases. Hence, the inhibitor anions should be harder bases than the aggressive anions, since they must preferentially bind to the highly oxidized metal ions on the film surface. In particular, compounds containing carboxylic group have been reported to be effective inhibitors, thus hampering chloride -induced breakdown oxide film of various metals and alloys. This can be done Surface Modification of Biodegradable Magnesium Alloys by adsorption of carboxylate on the oxide film, since the carboxylate ions are harder bases than chloride. ${ }^{11}$

The self-assembling monolayers (SAMs) provide a convenient method for modifying surfaces and producing organized adherent films, which acts as effective barriers to the penetration of corrosive species like oxygen and aggressive ions. ${ }^{12}$ Self-assembled monolayer (SAM)-forming monomers consist of three domains: a terminal functional group that ultimately defines the exposed surface functionality, a hydrocarbon chain (typically oligomethylene) to promote monolayer packing and organization, and an anchoring group responsible for the specific chemical interactions with the substrate. ${ }^{9}$ The main characteristics of the SAMs are: (1) the film forms spontaneously through a simple chemical adsorption and strongly adheres to the metal surface; (2) film formation is conformal allowing objects of any shape to be coated; (3) the thickness of the film can be controlled at the nanolevel by selecting adsorbates; (4) the films are densely packed and crystalline; (5) the chemical composition of the film can be tailored by design and synthesis of adsorbates. ${ }^{13}$ The facile use and intrinsic versatility of SAMs have made them a key ingredient of surface science. Self-assembly on a surface results from the interplay of (i) the affinity of the head group for the surface, which imparts the orientation of the adlayer and templates the structure in the case of crystalline surfaces, (ii) the non-covalent lateral interactions between the chains, that stabilize the structure and yield molecular order, and (iii) the intramolecular interactions which determine the fine details of the super-lattice structure (e.g. tilt-angle, surface lattice reconstruction). ${ }^{14}$ SAM surface functionalisation is convenient for defining the chemistry of surfaces that are far from ideal, like the technological surfaces that are either polycrystalline or amorphous, often exposed to ambient contamination (SAM molecules will "clean" out physisorbed and even strongly adsorbed contaminants), or processed and used in environments less controlled than ultra-high vacuum conditions. ${ }^{15}$ Modification of oxide surfaces has typically been performed using silanes, carboxylic acids, and phosphonic acids. ${ }^{16}$ The preparation of alkylphosphonic acid SAMs on magnesium alloys by vapor deposition and simple immersion methods and by an immersion method followed with heat treatment has been reported by Ishizaki et al ${ }^{17,18}$ and by Grubač et $\mathrm{al}^{19}$, respectively. Organic phosphonic acids form a strong bond with metal oxides, and the ad- sorption rate and stability strongly depends on the density of hydroxyl groups. ${ }^{3}$ The interaction (bonding mode) varies among surfaces, and may be monodentate, bidentate or tridentate. ${ }^{20}$ The Langmuir-Blodgett method ${ }^{21}$ and the tethering by aggregation and growth (T-BAG) method ${ }^{22}$ are two typical SAMs techniques used for modification of inorganic materials surface.

The advantage of T-BAG method is that the organic functional groups can be directly transverse to the substrates without promoting surface activation or applying of pressure. ${ }^{3}$ The purpose of this study is to improve the surface chemical stability and enhance the corrosion resistance of biodegradable magnesium and magnesium AZ91D alloy within physiological environments. The corrosion resistance of the surface coated AZ91D alloy was investigated in a standard simulated body fluid (Hanks' solution). Here we report the formation and characterization of covalently bounded SAMs of organic acids on the native oxide surface of $\mathrm{Mg}$ and $\mathrm{Mg}$ alloy (AZ91D).

\section{Experimental}

The AZ91D alloy (wt.\%: Al 8.6, Mn 0.19, Zn 0.51, Si $0.05, \mathrm{Cu} 0.025$, and $\mathrm{Fe} 0.004$ ) and commercial pure magnesium (wt.\%: Mn 0.1, Cu 0.02, Pb 0.01, Sn 0.01, and $\mathrm{Na} 0.006$ ) were used in this study. The working electrodes, with surface area of $0.235 \mathrm{~cm}^{2}$, were sealed into glass tubes with Polirepar S. They were abraded with fine emery paper, polished with alumina powder down to $0.05 \mu \mathrm{m}$, degreased in ethanol in an ultrasonic bath, rinsed with distilled water, and dried in a stream of nitrogen. The ethanolic solutions of each organic acids used to form the SAM by T-BAG method were: $1.0 \mathrm{mM}$ palmitic acid (PA, $\left.\mathrm{CH}_{3}\left(\mathrm{CH}_{2}\right)_{14} \mathrm{COOH}\right), 1.0 \mathrm{mM}$ stearic acid (SA, $\left.\mathrm{CH}_{3}\left(\mathrm{CH}_{2}\right)_{16} \mathrm{COOH}\right), 0.7 \mathrm{mM}$ dodecylphosphonic acid (DDPA, $\left.\mathrm{CH}_{3}\left(\mathrm{CH}_{2}\right)_{11} \mathrm{PO}(\mathrm{OH})_{2}\right)$ and $0.7 \mathrm{mM}$ octadecylphosphonic acid (ODPA, $\left.\mathrm{CH}_{3}\left(\mathrm{CH}_{2}\right)_{17} \mathrm{PO}(\mathrm{OH})_{2}\right)$.

Schematic T-BAG method is shown in Figure 1. The freshly prepared electrode is held vertically in an alcoholic solution of the corresponding acid temperature $60^{\circ} \mathrm{C}$. During self-assembling, during $2 \mathrm{~h}$, ethanol is allowed to evaporate slowly, as long as the level of alcoholic solution did not fall below the level of the electrode, or until the electrode did not stay at the "dry". After SAM forming electrodes were rinsed with distilled water and air dried. The treated sample was then heated at $140{ }^{\circ} \mathrm{C}$ for 24 hours. For comparison of the impedance spectra, electrode materials were kept during 2 hours in alcohol and equally thermally treated (blanc probe).

Molecular modeling of organic acid molecules was performed by using the Semiempirical program from the HyperChem 6.0.3. The FTIR spectra were recorded in the $4000-650 \mathrm{~cm}^{-1}$ region using Horizontal Attenuated Total Reflectance (HATR) method on a Perkin-Elmer Spectrum One FTIR spectrometer. 
The corrosion resistance of $\mathrm{Mg}$ and AZ91D alloy was investigated at $37^{\circ} \mathrm{C}$ in a Hanks' solution, $\mathrm{pH}$ 6.67, with following composition $\left(\mathrm{g} \mathrm{L}^{-1}\right)$ : $\mathrm{NaCl} 8.00, \mathrm{KCl} 0.40, \mathrm{NaH}-$ $\mathrm{CO}_{3} 0.35, \mathrm{NaH}_{2} \mathrm{PO}_{4} \times \mathrm{H}_{2} \mathrm{O} 0.25, \mathrm{Na}_{2} \mathrm{HPO}_{4} \times 2 \mathrm{H}_{2} \mathrm{O} 0.06$, $\mathrm{CaCl}_{2} \times 2 \mathrm{H}_{2} \mathrm{O} 0.19, \mathrm{MgCl}_{2} 0.19, \mathrm{MgSO}_{4} \times 7 \mathrm{H}_{2} \mathrm{O} 0.06$, and glucose 1.00. All chemicals were of p.a. purity. The experiments were carried out in a standard three-electrode cell. The counter electrode was a large area platinum electrode and the reference electrode, to which all potentials are referred, was $\mathrm{Ag} / \mathrm{AgCl} / 3 \mathrm{M} \mathrm{KCl}(209 \mathrm{mV}$ vs. SHE). Before measurements the electrodes were stabilized for $30 \mathrm{~min}$ in the Hanks' solution.

The electrochemical impedance spectroscopy (EIS) measurements were performed at the open circuit potential (OCP) with an ac voltage amplitude of $\pm 10 \mathrm{mV}$ in the frequency range from $100 \mathrm{kHz}$ to $0.1 \mathrm{~Hz}$. Measurements were carried out using a Solartron SI 1287 electrochemical interface and a Solartron SI 1255 frequency response analyzer. The EIS data were fitted using the complex non-linear least squares fit analysis software Zview. ${ }^{23}$ The numerical values of impedance parameters were determined with a standard deviation $\chi^{2}$ of the order of $10^{-5}$, and the relative error of each element was less than $5 \%$.

\section{Results and Discussion}

\section{1. Preparation of Self-Assembled Monolayers}

T-BAG is a simple technique of self-organization of amphiphilic molecules at the air solvent interface performed under ordinary laboratory conditions at atmospheric pressure and at lower temperatures. SAMs bound directly to the spontaneously formed oxide film whose growth is not limited by surface $\mathrm{OH}$ content (as in the case of the silylation process), and densely packed surface bound monolayer films can be obtained. Amphiphilic molecules are transferred from an alcoholic solution to the metal substrate surface in inverse analogy to Langmuir-Blodgett methods which contributes the organized aggregation of the dissolved polar parts of amphiphilic molecules at the air alcohol interface. ${ }^{24}$ When the self-assembling process substrate is heated at $140{ }^{\circ} \mathrm{C}$ the surface adsorbed amphi-

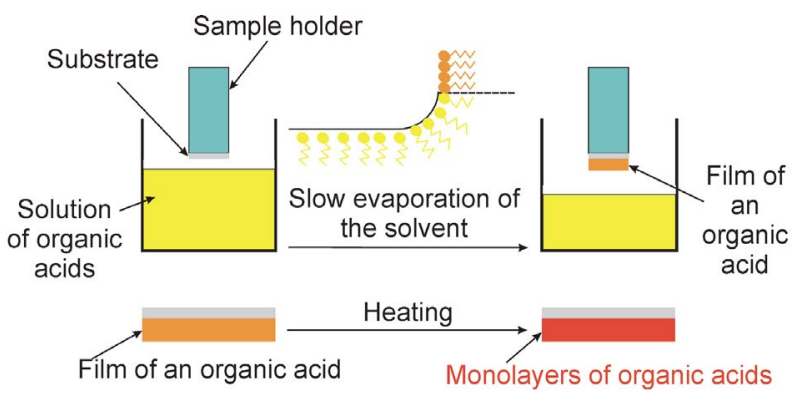

Figure 1. The T-BAG method setup. ${ }^{22}$ philic molecules converts to the surface-bound, thus monolayers become stable. ${ }^{22,24-26}$

\section{2. EIS Measurements - Carboxylic Acids SAM}

The AZ91D alloy surface was modified with carboxylic acids SAM using the T-BAG method ${ }^{22}$ and the corrosion resistance of the modified electrodes was tested with EIS. Impedance spectra for the unmodified and modified AZ91D alloy are shown in Figure 2.

In Nyquist's diagram of the impedance spectra shown in Figure 2 it can be seen that the fatty acid SAMs formed by the T-BAG method increase the polarization resistance of the AZ91D alloy and thus increase its corrosion resistance in the Hanks' solution. AZ91D alloy samples modified with carboxylic acids SAM in Bode diagram in the low frequency region have higher overall impedance in compared to the unmodified sample. In Nyquist's diagram, an increase in the diameter of the capacitive semicircle with an increase in the length of the alkyl chain is observed. The increase of the polarization resistance value refers to the better protective properties of stearic acid SAM formed by the T-BAG method compared to the palmitic acid SAM
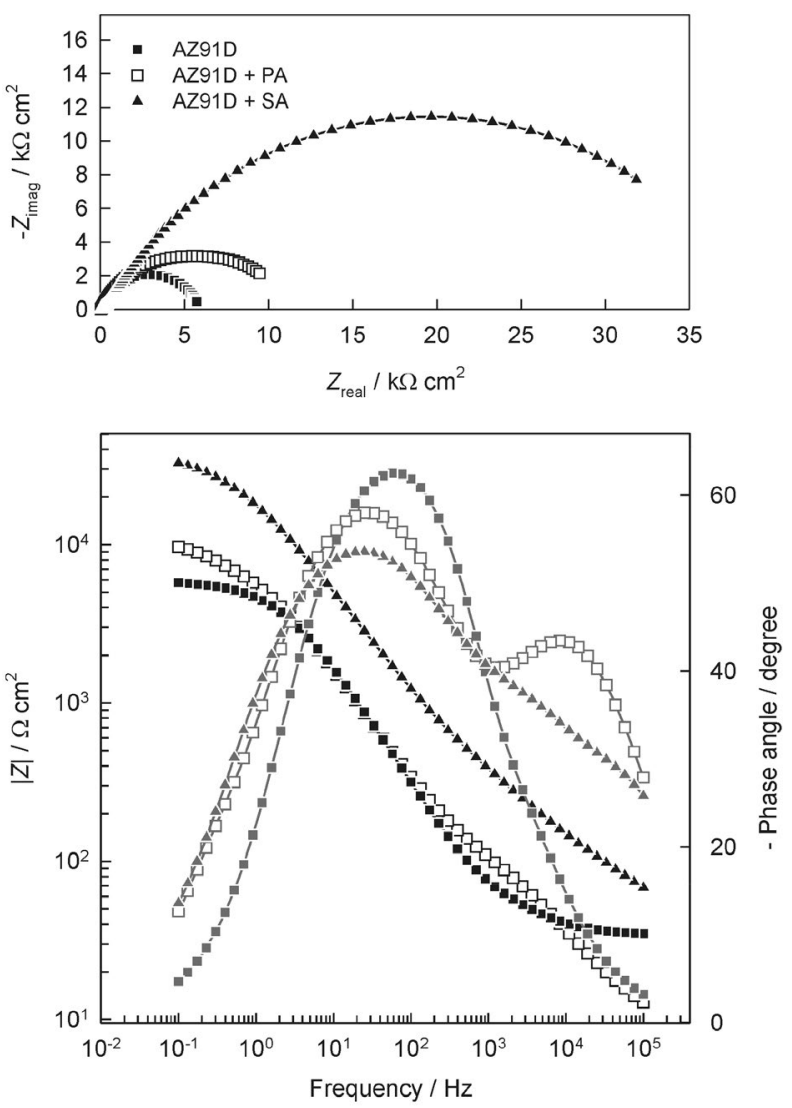

Figure 2. Nyquist and Bode plots of the unmodified AZ91D alloy and AZ91D alloy modified with the carboxylic acids SAM recorded in Hanks' solution at the open circuit potential. 
formed under the same conditions. The phase angle vs. $\log f$ dependence indicates the capacitance behavior that is expressed in a much wider medium frequency range for electrodes modified with carboxylic acids SAM.

By modifying the AZ91D alloy with carboxylic acids SAM formed by T-BAG method third time constant becomes more pronounced. Therefore, the impedance spectra of the AZ91D alloy electrode modified with carboxylic acids SAM are fitted with an equivalent circuit which consists of three time constants. The total impedance, $Z$ of the investigated electrochemical system is described by the transfer function: the carboxylate film and the efficacy of the AZ91D alloy protection in Hanks' solution. The AZ91D alloy modified with stearic acid SAM has almost the four times higher polarization resistance than the alloy modified with palmitic acid SAM. In addition to increases of the polarization resistance, increasing the length of alkyl chain decreases the capacitance of the film. Low capacity values and increased resistance of carboxylate SAM by prolongation of the alkyl chain result in denser packing and greater regulation of SAM due to the reorganization of the alkyl chains with the van der Waals forces. ${ }^{13}$

$$
Z(j \omega)=R_{e l}+\left\{Q_{1}(j \omega)^{n_{1}}+\left\{R_{1}+\left\{Q_{2}(j \omega)^{n_{2}}+\left\{R_{2}+\left[Q_{3}(j \omega)^{n_{3}}+R_{3}^{-1}\right]^{-1}\right\}^{-1}\right\}^{-1}\right\}^{-1}\right\}^{-1}
$$

The first parallel $R_{1}-C P E_{1}$ combination describes the process of dissolving magnesium at the magnesium/electrolyte interface. $\mathrm{R}_{1}$ is a charge transfer resistance; $C P E_{1}$ is a double layer capacity. The second parallel $R_{2}-C P E_{2}$ combination is associated with the surface film, where $R_{2}$ is the surface film resistance, and $C P E_{2}$ is its capacity. The third parallel $\mathrm{R}_{3}-\mathrm{CPE}_{3}$ combination represents carboxylic acid SAM (Figure 3 ). ${ }^{27}$

The constant phase element (CPE) was used instead of capacitance because the associated distribution of time constants provides an improved fit. ${ }^{28}$ Its impedance is equal to $Z(\mathrm{CPE})=\left[\left(Q(\mathrm{j} \omega)^{n}\right]^{-1}\right.$; where $Q$ is the constant, $\omega$ is the angular frequency, and $n$ is the CPE power. When $n=1, Q$ represents the pure capacitance, while for $n \neq 1$ the system shows behavior that has been attributed to the surface heterogeneity ${ }^{29}$ or to the continuously distributed time constants for charge transfer reactions. ${ }^{30}$ The numerical values of impedance parameters obtained by fitting procedure are listed in Table 1 . The value of polarization resistance $\left(R_{\mathrm{p}}\right)$, which represents the corrosion resistance, is equal to the sum of $R_{1}$ and $R_{2}$ for spontaneously passivated specimens and to the sum $R_{1}+R_{2}+$ $R_{3}$ for specimens modified with SAM. The values of the inhibition efficiency of magnesium corrosion in Hanks' solution are also presented in the Table 1 . The inhibition efficiency $(\eta \%)$ of modified surface layers were calculate using the numerical values of $R_{\mathrm{p}}$ according to the expression:

$$
\eta(\%)=\left[\frac{\left(R_{p}^{p}-R_{p}^{n}\right)}{R_{p}^{p}}\right] \times 100
$$

where $R_{p}^{p}$ and $R_{p}^{n}$ are the polarization resistance values of specimens modified with SAMs and those spontaneously passivated, respectively.

The protection efficiency of the AZ91D alloy modified with the palmitic acid SAM is $47 \%$, while the protection efficiency of the AZ91D alloy modified with stearic acid SAM is $85 \%$.

These obtained values indicate that increasing of the length of the alkyl chain increases the barrier properties of
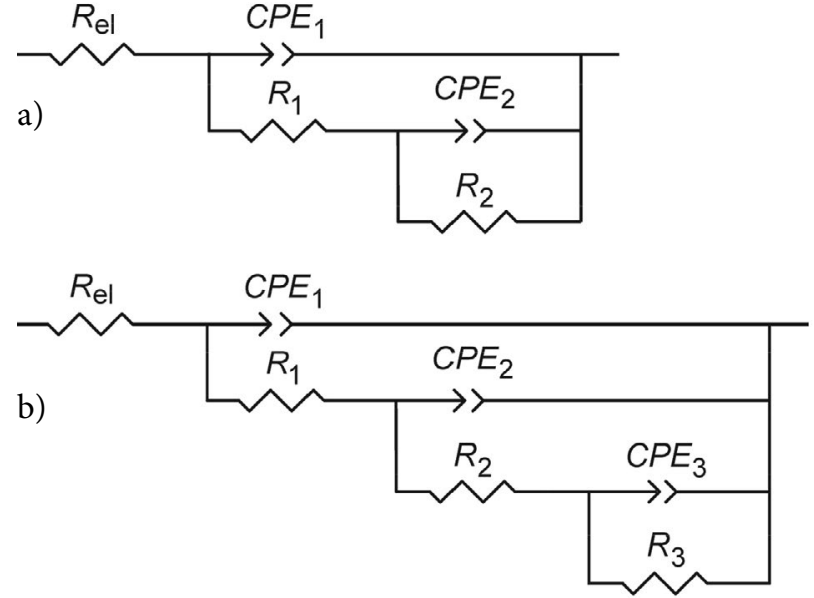

Figure 3. EECs used to fit impedance data.

The corrosion resistance of the unmodified magnesium and magnesium modified with carboxylic acids SAM using the T-BAG method was also tested with EIS. The impedance spectra which had a very similar shape to those of unmodified AZ91D alloy and which are therefore fitted with the same EECs (Figure 3a) are not shown here.

\section{3. EIS Measurements - Phosphonic Acids SAM}

Figure 4 and Figure 5 represent Nyquist and Bode plots of AZ91D alloy and magnesium modified with DDPA and ODPA SAM formed by T-BAG method, respectively. For comparison, spectra of electrodes without SAM were recorded and shown. By modifying the AZ91D alloy with phosphonic acids SAM the third time constant becomes more apparent. The impedance spectra of modified AZ91D alloy shown in Figure 4 are therefore fitted with an electric equivalent circuit having three time constants (Figure 3b). In Nyquist plots shown in Figures 4 and 5 , there are two clearly separated capacitive semicircles, small in the high frequency region and large in 
Table 1. The protection efficiency $(\eta \%)$ of modified surface layers and optimal values of the equivalent circuit parameters wherewith the fitting of the impendence spectra of the unmodified AZ91D alloy and AZ91D alloy modified with palmitic acid (PA) SAM and stearic acid (SA) SAM formed by the T-BAG method in Hanks' solution, pH 6.67 are performed.

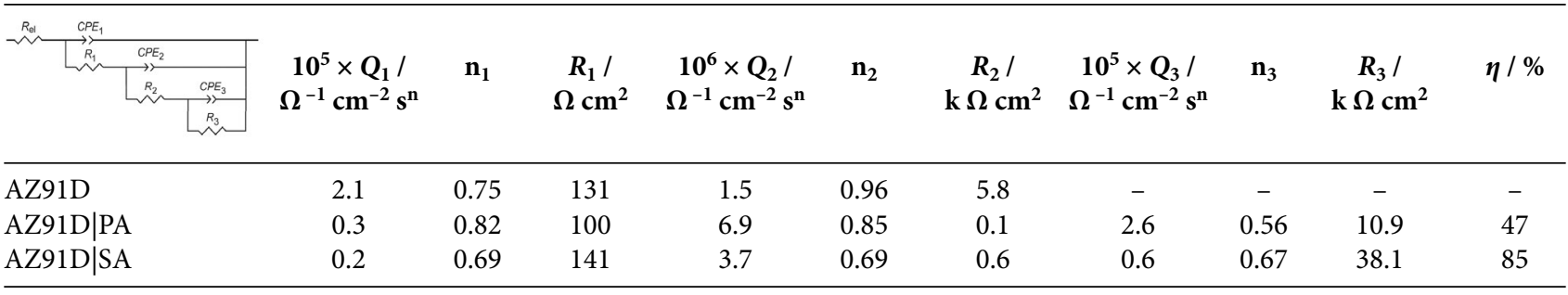

$R_{\mathrm{el}}=26 \Omega \mathrm{cm}^{2}$
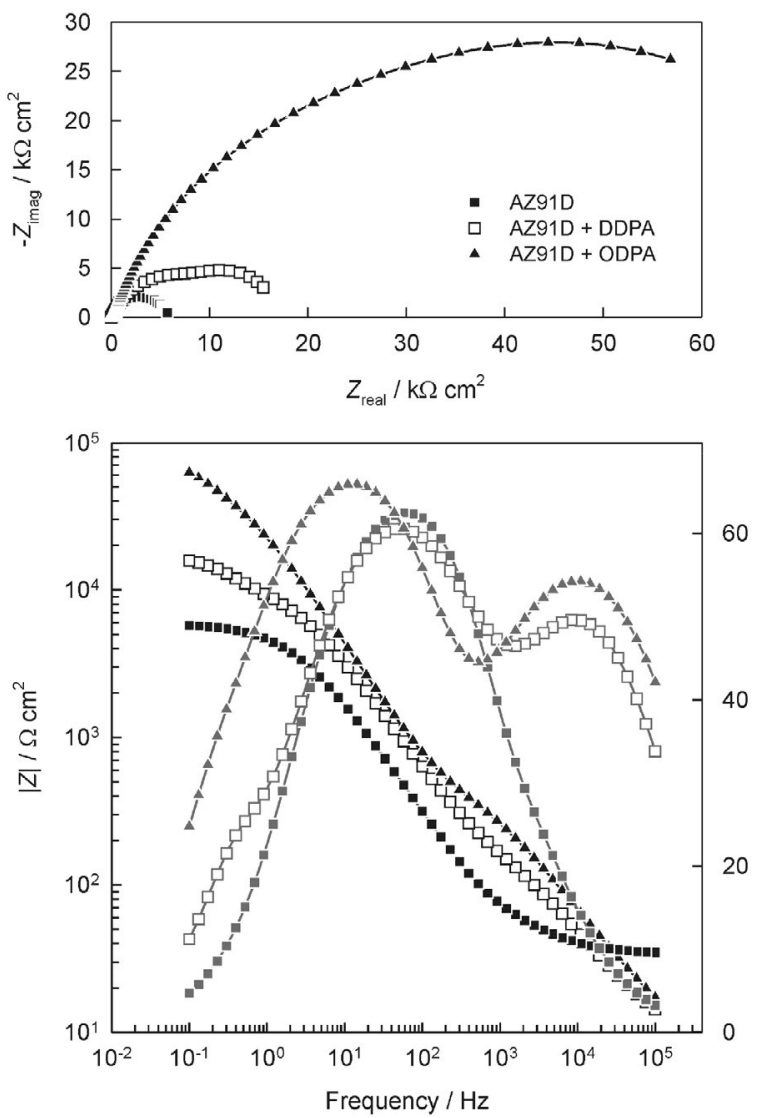

Figure 4. Nyquist and Bode plots of unmodified AZ91D alloy and AZ91D alloy modified with phosphonic acids SAM recorded in the Hanks' solution at the open circuit potential.

the medium and low frequencies region. As a result of the adsorption of phosphonic acid, the capacitive semicircles (Nyquist plot) increases while the capacitance behavior and the phase angle maxima (Bode plot) move to lower frequencies region and occur in a wider frequency range indicating an increase in polarization resistance. In Figures 4 and 5 in the medium frequency region of the Bode plot, it can be seen the maxima and linear dependence log $|Z|$ vs $\log f$ with an slop close to -1 which is the result of the capacitive behavior of the protected electrode. In the high frequency region, the dependence $\log |Z|$ vs $\log f$ does not
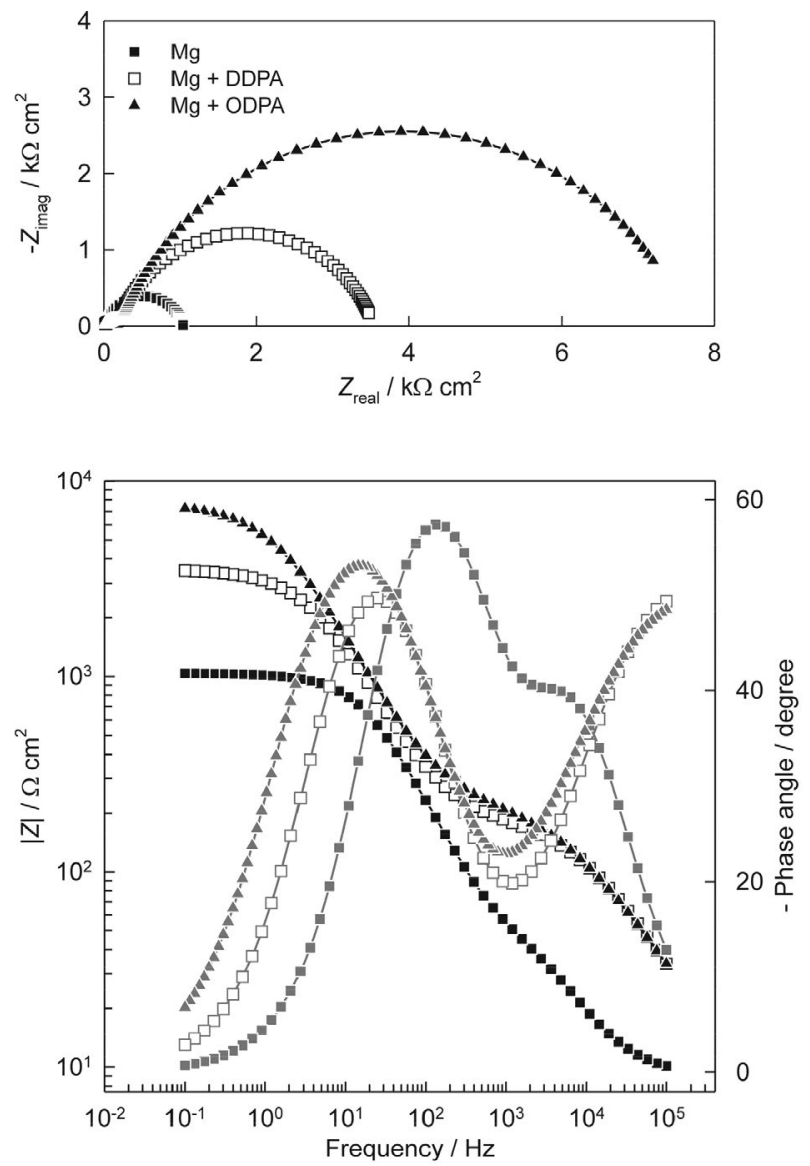

Figure 5. Nyquist and Bode plots of unmodified magnesium and magnesium modified with phosphonic acids SAM recorded in the Hanks' solution at the open circuit potential.

achieve frequency independence, i.e. flattening, and the phase angle contains an additional maximum. In Nyquist plot, it can also be seen that the polarization resistance of the electrodes modified with SAMs is greater than the polarization resistance of the unprotected electrodes.

Values of the impedance parameters are given in Table 2 (Figure 4) and Table 3 (Figure 5). The $R_{\mathrm{p}}$ values for spontaneously passivated alloy specimens equal to $5.9 \mathrm{k} \Omega \mathrm{cm}^{2}$ and very low $R_{\mathrm{p}}$ value for $\mathrm{Mg}\left(\sim 1 \mathrm{k} \Omega \mathrm{cm}^{2}\right)$ can be observed. The AZ91D alloy has two phase microstructure typically consisting of a matrix of $\alpha$ grains with 
Table 2. The protection efficiency $(\eta \%)$ of modified surface layers and optimal values of the equivalent circuit parameters wherewith the fitting of the impendence spectra of the unmodified AZ91D alloy and AZ91D alloy modified with dodecylphosphonic acid (DDPA) SAM and octadecylphosphonic acid (ODPA) SAM formed by the T-BAG method in Hanks' solution, pH 6.67 are performed.

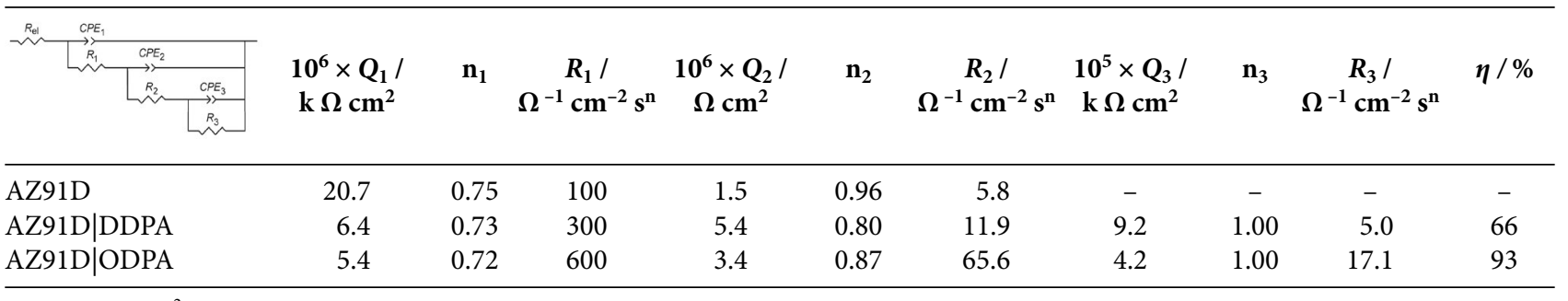

$R_{\mathrm{el}}=10 \Omega \mathrm{cm}^{2}$

Table 3. The protection efficiency $(\eta \%)$ of modified surface layers and optimal values of the equivalent circuit parameters wherewith the fitting of the impendence spectra of the unmodified magnesium and magnesium modified with dodecylphosphonic acid (DDPA) SAM and octadecylphosphonic acid (ODPA) SAM formed by the T-BAG method in Hanks' solution, pH 6.67 are performed.

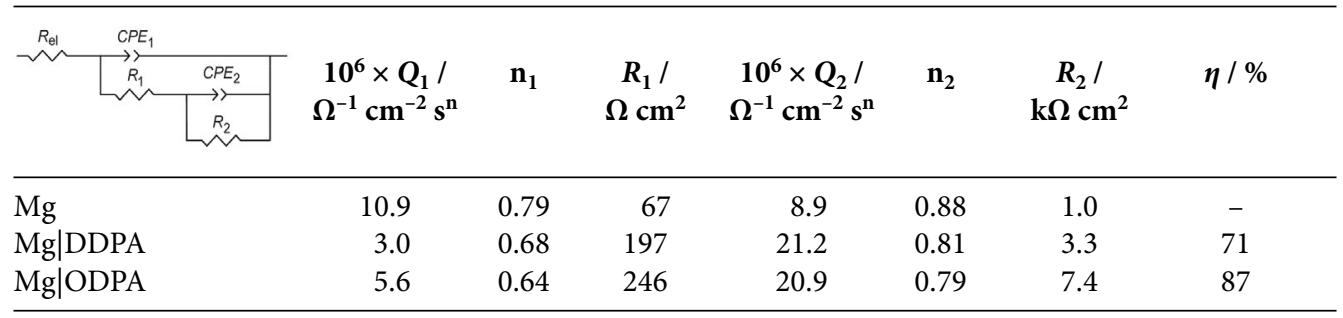

$R_{\mathrm{el}}=9 \Omega \mathrm{cm}^{2}$

the $\beta$ phase (the intermetallic $\mathrm{Mg}_{17} \mathrm{Al}_{12}$ ) along the $\alpha$ grain boundaries. ${ }^{31}$ The $\beta$-phase is cathodic with the respect to the matrix $\alpha$ phase and exhibits a passive behavior over a wider $\mathrm{pH}$ range than either of its components $\mathrm{Al}$ and Mg. ${ }^{32}$ It has been found that $\mathrm{Mg}_{17} \mathrm{Al}_{12}$ is inert in chloride solutions and, if spread over the a matrix, it acts as an effective corrosion barrier. ${ }^{32,33}$ This is the main reason why alloy specimens show a highest corrosion resistance in the Hanks' solution in comparison to that unmodified magnesium. The $R_{\mathrm{p}}$ values for specimens additionally modified with DDPA SAM are $17.2 \mathrm{k} \Omega \mathrm{cm}^{2}$ (Table 2) and 3.5 $\mathrm{k} \Omega \mathrm{cm}^{2}$ (Table 3) respectively, while those for specimens additionally modified with ODPA SAM are equal to 83.3 $\mathrm{k} \Omega \mathrm{cm}^{2}$ (Table 2) and $7.6 \mathrm{k} \Omega \mathrm{cm}^{2}$ (Table 3), respectively. Protection efficiencies of DDPA SAM on the AZ91D alloy surface and magnesium surface equal to $66 \%$ and $71 \%$, respectively while those for ODPA SAM on the AZ91D alloy surface and magnesium surface equal to $93 \%$ and $87 \%$, respectively.

The greatest value of polarization resistance (i.e., the best protective properties) shows AZ91D alloy modified with ODPA SAM formed by T-BAG method. Therefore, an influence of time exposed to the Hanks' solution and usage of the different surface modification methods on the electrochemical behavior of the AZ91D alloy modified with the ODPA SAM formed by T-BAG method was investigated by electrochemical impedance spectroscopy. Impedance spectra were recorded in a Hanks' solution of $\mathrm{pH} 6.67$ at $37^{\circ} \mathrm{C}$ at an open circuit potential in the time interval of 10 minutes to 240 minutes. Nyquist and Bode plot of the modified AZ91D alloy after different exposure times to the Hanks' solution is shown in Figure 6. In Nyquist plot, two capacitive semicircles can be observed, small in the high frequency region and large in the medium and low frequencies region. The polarization resistance of the electrode is increased by increasing of the time exposed to the Hanks' solution up to 120 minutes of electrode stay within Hanks' solution. For longer periods of exposure times, the polarization resistance decreases, indicating the decrease of ODPA SAM protective behavior. In medium frequencies region, the expressed capacitance behavior of the electrodes is represented by the linear dependence log $|Z|$ vs. $\log f$ with a slope of less than -1 and a phase angle of about $70^{\circ}$. The deviation from the ideal capacitive behavior to which the inclination slope less than -1 is particularly pronounced for longer periods of exposure times (over 120 minutes) to Hanks' solution and is most likely due to the disruption of phosphonate SAM due to accumulation of corrosive products on the surface of the electrode causing the appearance of a third time constant. ${ }^{34}$ Therefore, the impedance spectra up to the exposure times of 120 minutes are analyzed with EEC which contains two time constants, and the impedance spectra obtained for longer exposure times with EEC which contains three time constants.

As can be seen from Figure 7 the T-BAG method as well as the immersion method results in the formation of stable phosphonate SAMs on the surface of AZ91D alloys which are an effective barrier between AZ91D alloys and 

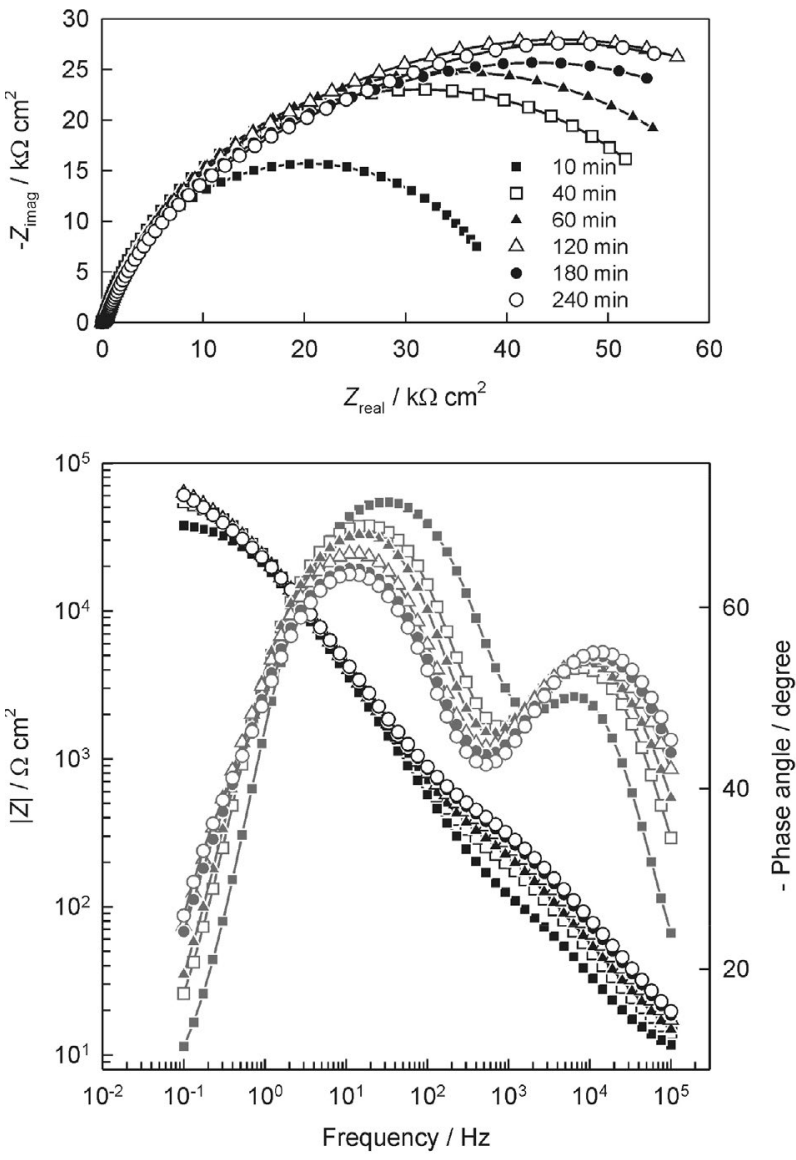

Figure 6. Nyquist and Bode plot of the AZ91D alloy modified with ODPA SAM recorded in Hanks' solution at the open circuit potential during its stay within the electrolyte.

electrolytes. The highest values of the polarization resistance of the AZ91D|oxide|SAM system were obtained for ODPA SAM formed on the AZ91D alloy by the T-BAG method.

Therefore, with the T-BAG method a better structural reorganization of phosphonate films which cause arrangeous and homogeneous structure with a smaller number of defects is achieved. ${ }^{22}$

\section{4. Molecular Modeling}

The stability of the adsorption bond is related to Pearson's HSAB principle. ${ }^{35-37}$ Soft-soft and hard-hard interactions are favored with respect to crossed interactions. The hard-hard and soft-soft bond character relates to ionic (charge controlled) and covalent (frontier controlled) reactions, respectively. ${ }^{38}$ Acidity or basicity of the metal and the adsorbent molecule should be considered as acidic sites that favor adsorption of basic adsorbents, and as basic sites that favor adsorption of acidic adsorbents. In terms of Lewis acidity, metal ions at a high oxidation state or coordinatively unsaturated, as well as anionic vacancies
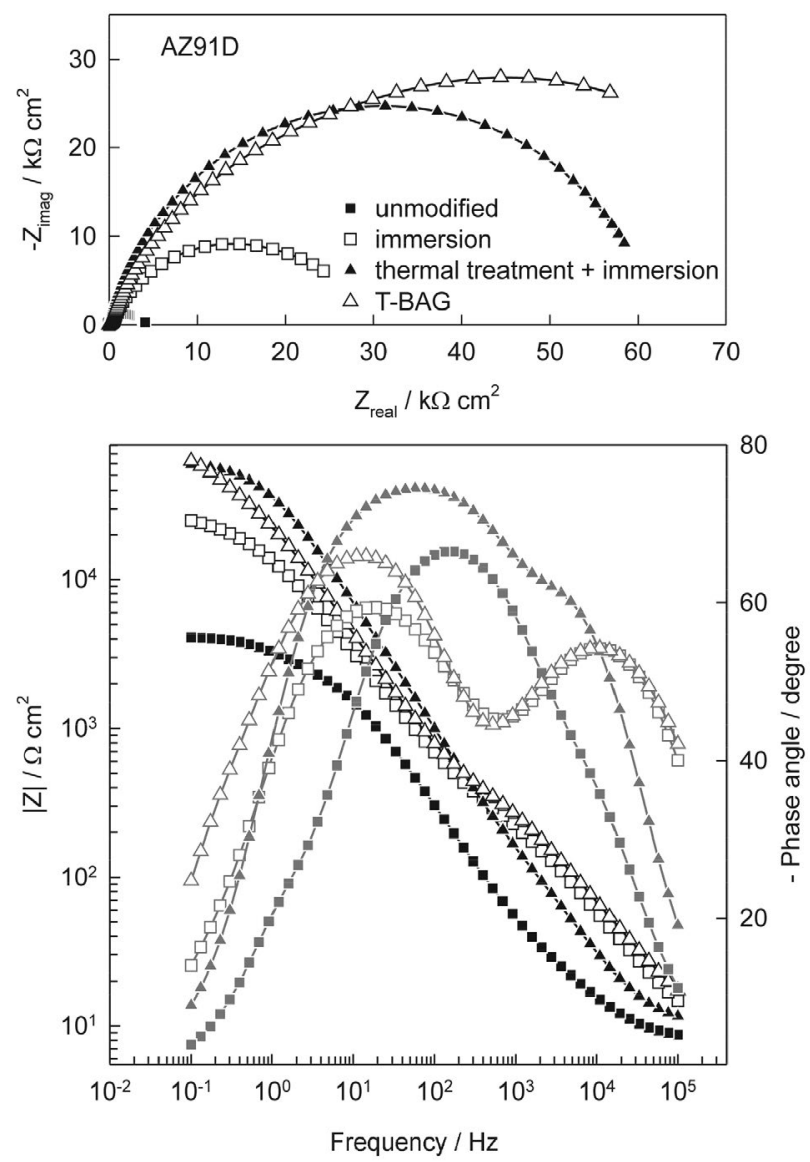

Figure 7. Nyquist and Bode plots of unmodified AZ91D alloy and AZ91D alloy modified with ODPA SAM recorded in Hanks' solution at the open circuit potential. (Three different surface modification methods are indicated.)

can be considered as acidic centers. On the other hand, oxygenated anions and hydroxyl groups are basic sites. The outer sphere complexes (the ligand weakly interacts with surface groups) and the inner sphere complexes (the ligand is coordinated with the metal) may form between organic acids and oxidized metal surface. The principle of electroneutrality implies that in the bulk of the oxide, charge of the metal ion is compensated by the charge of the surrounding oxygen atoms. ${ }^{11}$ Negative charge of a carboxylate group $\left(\mathrm{COO}^{-}\right)$is distributed over oxygen atoms (Figure 8) Hence, the charge is almost neutralized by the Pauling charge of magnesium and equally distributed over the ligands, which is favorable for adsorption. The absolute hardness, $\eta$ defined by Pearson is associated with the ionization potential, $I$ and the electron affinity $A$, and is given by the expression: ${ }^{36-38}$

$$
\eta=\frac{(I-A)}{2}
$$

According to the Koopman's theorem, ${ }^{39}$ the $I$ and $A$ are connected to the frontier orbital energies: 


$$
I=E_{\text {номо }} \text { and } A=-E_{\text {LUMO }}
$$

For anions, $A$ is a large negative number consequently, $\eta$ is also quite large. Because it's known that the hardness is independent of charge the approximation can be made for a number of ions of interest. Proportionality can be assumed between for an anion and for the corresponding radical that allow rating of anions in order of increasing chemical hardness in the absence of added interelectronic repulsion. ${ }^{11}$

Table 4 lists the chemical hardness, $\eta$ of the investigated acids. Between the oxidized $\mathrm{Mg}$ alloy surface and the inhibitors hard acid-hard base interactions were found.

In a corrosion system containing an inhibitor, the molecular structure of the inhibitor also plays an important role in determining its mode of adsorption on the corroded surface. Hydrophobicity, solubility, molecular spatial structure and molecular electronic structure can be related to corrosion inhibitor properties. Quantum chemical methods enable the definition of a large number of molecular quantities characterizing such as reactivity, shape, and binding properties of a molecule. ${ }^{40}$

Carboxylic and phosphonic acids were molecular modeled by using Semi-empirical program from the HyperChem package in order to obtain the relationship between inhibition efficiency and their electronic properties. Geometry optimizations of organic acids were performed by theoretical calculations of semi-empirical method; AM1, PM3 and MNDO level. The highest occupied molecular orbital (HOMO) and the lowest unoccupied molecular orbital (LUMO) are performed. The optimized molecular structures of compounds are shown in Figure 8. The calculated quantum chemical parameters $E_{\mathrm{HOMO}}, E_{\mathrm{LUMO}}, \Delta E$ and $\mu$ (dipole moment) are listed in Table 4 . It has been reported in the literature that high values of $E_{\mathrm{HOMO}}$ are likely to indicate a tendency of the molecule to donate electrons to appropriate acceptors with low energy and the higher the corrosion inhibition efficiency. In addition, the energy of the lowest unoccupied molecular orbital ( $\left.E_{\mathrm{LUMO}}\right)$ indicates the easier the acceptance of electrons from metal surface, as the energy gap $\left(\Delta E=E_{\mathrm{LUMO}}-E_{\mathrm{HOMO}}\right)$ decreased and the efficiency of inhibitor improved. ${ }^{41,42}$ The results of Table 4 show that the $E_{\mathrm{LUMO}}$ for ODPA (for all method) is lower than DDPA, SA and PA has the lowest energy gap. The results are agreed with the experimental results (EIS) which indicate that ODPA could have better performance as corrosion inhibitor. Some authors showed that an increase of the dipole moment leads to decrease of inhibition and vice versa, suggesting that lower values of the dipole moment will favor accumulation of the inhibitor in the surface layer. In contrast, the increase of the dipole moment can lead to increase of inhibition and vice versa, which could be related to the dipole-dipole interaction of molecules and metal surface. ${ }^{43}$ The lower value of $\mu$ obtained for ODPA is coherent with the first explanation indicating accumulation of the inhibitor in the surface layer in comparison to other organic acids. The results of Table 4 show that the calculated quantum chemical parameter obtained with different methods has the same trends. The regions of highest electron density (HOMO) are the sites at which electrophiles attack with the superlative ability to bond to the metal surface. ${ }^{43}$ The results show that the highest occupied molecular orbital (HOMO) density is oriented towards the electrode and that HOMO and LUMO orbitals for investigated organic acids are localized and saturated on a carboxyl, i.e., phosphonic head group. Hence it should be expecting that the carboxylate group i.e. phosphonate head group is attached by its oxygen atoms to $\mathrm{Mg}$ ions. The circumstances of adsorption of these acids are shown in Figure 8.

Table 4. Quantum chemical parameters of used compounds obtained from quantum method.

\begin{tabular}{llccccc}
\hline $\begin{array}{l}\text { Met- } \\
\text { hod }\end{array}$ & $\begin{array}{l}\text { Com- } \\
\text { pound }\end{array}$ & $\begin{array}{c}E_{\text {HOMO }} \\
(\mathbf{e V})\end{array}$ & $\begin{array}{c}E_{\mathrm{LUMO}} \\
(\mathrm{eV})\end{array}$ & $\begin{array}{c}\Delta E \\
(\mathrm{eV})\end{array}$ & $\begin{array}{c}\eta(\mathrm{eV}) \\
(\mathrm{eV})\end{array}$ & $\begin{array}{c}\boldsymbol{\mu} \\
(\mathrm{D})\end{array}$ \\
\hline AM1 & PA & -4.666 & 0.821 & 3.844 & 1.922 & 3.616 \\
& SA & -7.981 & 1.948 & 6.033 & 3.016 & 2.210 \\
& DDPA & -7.531 & 1.401 & 6.130 & 3.065 & 1.208 \\
& ODPA & -8.132 & 0.425 & 7.706 & 3.853 & 0.535 \\
\hline PM3 & PA & -6.582 & 1.035 & 5.546 & 2.773 & 3.396 \\
& SA & -8.053 & 2.237 & 5.817 & 2.908 & 1.624 \\
& DDPA & -6.861 & 0.906 & 5.955 & 2.977 & 1.044 \\
& ODPA & -7.423 & 0.037 & 7.386 & 3.694 & 0.490 \\
\hline MNDO & PA & -8.296 & 1.605 & 6.691 & 3.345 & 1.774 \\
& SA & -8.325 & 1.562 & 6.763 & 3.381 & 1.744 \\
& DDPA & -8.424 & -0.015 & 8.409 & 4.204 & 0.636 \\
& ODPA & -8.907 & -0.245 & 8.658 & 4.329 & 0.581 \\
\hline
\end{tabular}

\subsection{FTIR Characterization}

For obtaining information about a nature of attraction between acids and an oxide/hydroxide film on the surface, FTIR spectroscopy measurements were performed. The obtained spectra are presented in Figure 9.

Both FTIR spectra contain the stretching values $v(\mathrm{C}-\mathrm{H})_{\text {asymm. }} \leq 2918 \mathrm{~cm}^{-1}$ and $v(\mathrm{C}-\mathrm{H})_{\text {symm. }} \leq 2850 \mathrm{~cm}^{-1}$ which indicates the existence of a well organized monolayer, which is characterized by alkyl chains in an all-trans configuration that are all tilted from the normal to the surface at the same angle. ${ }^{44}$ FTIR spectra of the AZ91D alloy modified with SA SAM contains the peaks at 1558 $\mathrm{cm}^{-1}$ and at $1454 \mathrm{~cm}^{-1}$ correspond to the asymmetric and symmetric $\mathrm{COO}^{-}$stretching, respectively. The presence of these peaks and the lack of peaks corresponding to the $v(\mathrm{C}=\mathrm{O})$ stretching and $\mathrm{C}-\mathrm{O}-\mathrm{H}$ stretching indicate that the carboxylic head group is attached to the surface layer in a bidentate configuration. ${ }^{27,45,46}$ 


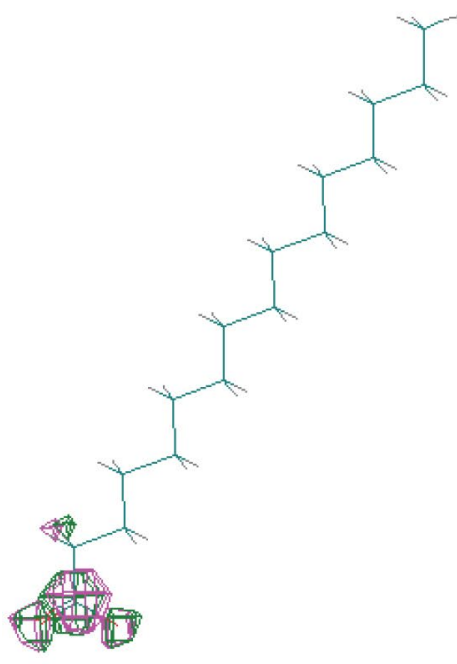

PA

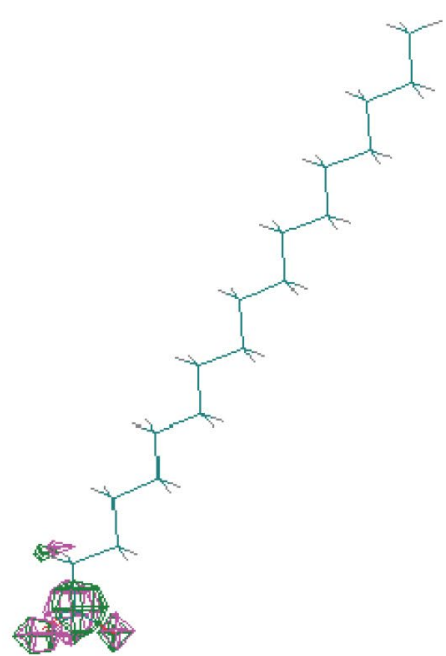

SA

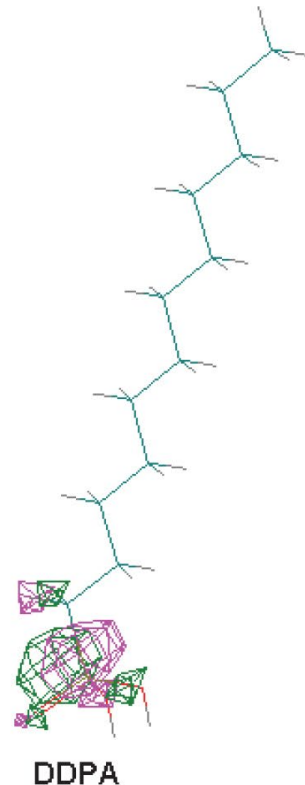

DDPA

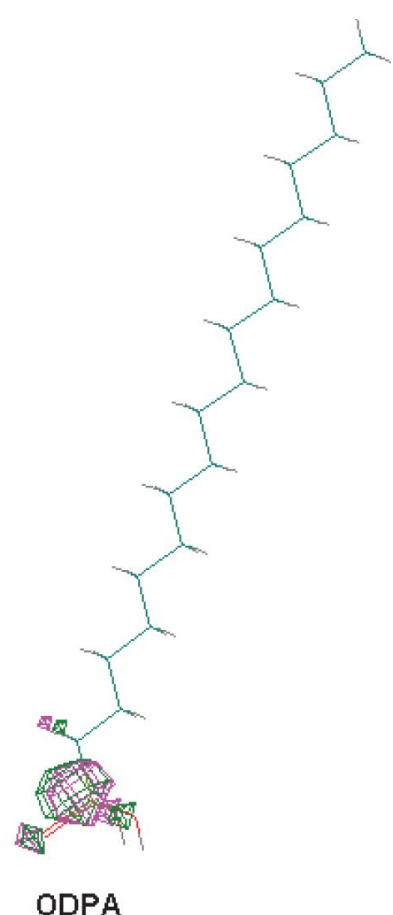

Figure 8. Geometry optimization of organic acids calculated by semi empirical method.

The PO region of the AZ91D alloy, on whose surface DDPA SAM was formed, contains peaks at $1105.1 \mathrm{~cm}^{-1}$ and $1019.1 \mathrm{~cm}^{-1}$ that can be attributed to the stretching vibration of the $\mathrm{P}-\mathrm{O}$ bond, which indicates that the phosphonic acid is on the oxidized AZ91D alloy surface, bond-

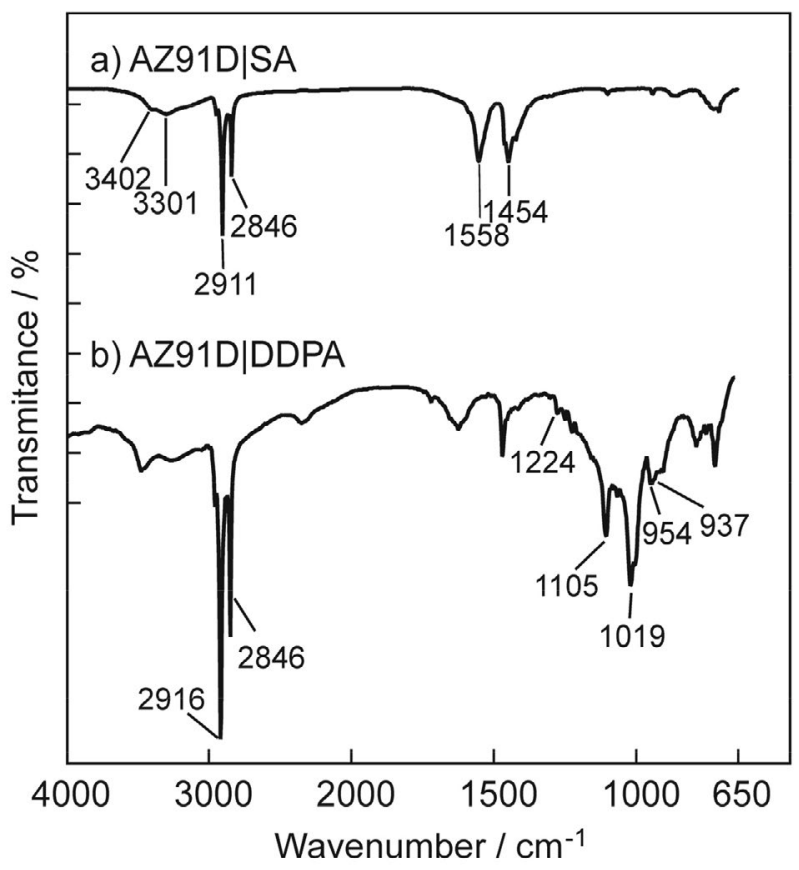

Figure 9. The FTIR spectra of AZ91D alloy modified with the SAM of: a) stearic acid (SA) and b) dodecylphosphonic acid (DDPA). ed through head group. ${ }^{47}$ However, the FTIR spectrum of AZ91D alloy surface modified with DDPA SAM contains peaks of weak intensity at $954 \mathrm{~cm}^{-1}$ and $937 \mathrm{~cm}^{-1}$ (corresponding to stretching vibration of the $\mathrm{P}-\mathrm{OH}$ bond) and a peak of weak intensity around $1224 \mathrm{~cm}^{-1}$ (corresponding to stretching vibration of the $\mathrm{P}=\mathrm{O}$ bond), which suggest the presence of a number of different binding modes in DDPA monolayers. ${ }^{48}$ The peak of low intensity at a wavenumber of about $2300 \mathrm{~cm}^{-1}$ in the FTIR spectrum of AZ91D alloy modified with DDPA SAM confirms the presence of free P-OH groups in DDPA SAM. ${ }^{47}$

The AZ91D alloy modified with PA SAM and AZ91D alloy modified with ODPA SAM were also characterized by FTIR spectroscopy. The FTIR spectra of the AZ91D alloy modified with PA (ODPA) SAM contain all significant peaks and the obtained wavenumber values agree well with the values for AZ91D alloy modified with SA (DDPA) SAM, respectively. These spectra due to a small percentage of transmittance are not shown here.

These results (compare the Figure 2 and Figure 4 and the Table 1 and Tabe 2) indicated that phosphonates allow the formation of more stable monolayers on oxide surfaces because phosphonic acids may form additional $\mathrm{P}-\mathrm{O}-\mathrm{M}$ bonds (bidentate or tridentate) with hydroxyl groups on the surface, leading to a higher stability compared to carboxylate monolayers on metal oxides. ${ }^{9}$

Phosphonic acids form robust monolayers without the need to resort to cross-linking, as is common, for example, in silane surface modification. ${ }^{49}$ 


\section{Conclusions}

In this work we presented surface modification of magnesium based materials, by self-assembled layer using T-BAG method, using four organic acids (two carboxylic and two phosphonic acids), in order to enhance the corrosion resistance.

Layers of these organic acids on magnesium based materials are investigated with FTIR and obtained results suggest that are organized as self-assembled monolayer by electrostatic attraction of functional groups of organic acids and $\mathrm{MgO} / \mathrm{Mg}(\mathrm{OH})_{2}$ film.

Corrosion resistance of SAMs formed on magnesium based materials are investigated by EIS in simulated body fluid electrolyte (Hanks' solution).

Obtained results reveal that most promisingly potential for corrosion inhibition of magnesium based materials has ODPA, due to longest chain and to the conversion of phosphonic group to phosphonate during preparation of SAM (formation of additional P-O-Metal bond).

Inhibiting potentials of used organic acids are evaluated by semiempirical methods computations of quantum chemical parameters and obtained results are in agreement with experimental data.

\section{References}

1. Y. Jang, B. Collins, J. Sankar, Y. Yun, Acta Biomater. 2013, 9, 8761-8770. DOI:10.1016/j.actbio.2013.03.026

2. R. Xiaodong, L. Xuesong, Y. Yue, Y. You, W. Hua, Rare Metal Mat. Eng. 2017, 46(1), 45-50.

3. C-W. Yang, C. Liu, D-J. Lin, M-L. Yeh, T-M. Lee, Sci. Rep-Uk. 2017, 7:16910, 1-13.

4. Y. Wan, G. Xiong, H. Luo, F. He, Y. Huang, X. Zhou, Materials and Design 2008, 29, 2034-3067.

DOI:10.1016/j.matdes.2008.04.017

5. G. Song, Corros. Sci. 2007, 49, 1696-1701.

DOI:10.1016/j.corsci.2007.01.001

6. K. Brunelli, M. Dabalà, I. Calliari, M. Magrini, Corros. Sci. 2005, 47, 989-1000. DOI:10.1016/j.corsci.2004.06.016

7. Y. Tamar, D. Mandler, Electrochim. Acta 2008, 53, 5118-5127. DOI:10.1016/j.electacta.2008.02.029

8. Z. Grubač, I. Škugor-Rončević, M. Metikoš-Huković, R. Babić, M. Petravić, R. Peter, J. Electrochem. Soc. 2012, 159, C253-C258. DOI:10.1149/2.047206jes

9. N. S. Bhairamadgi, S. P. Pujari, F. G. Trovela, A. Debrassi, A. A. Khamis, J. M. Alonso, A. A. A. Zahrani, T. Wennekes, H. A. Al-Turaif, C. van Rijn, Y. A. Alhamed, H. Zuilhof, Langmuir 2014, 30, 5829-5839. DOI:10.1021/la500533f

10. M. F. Montemor, M. G. S. Ferreira, Electrochim. Acta 2007, 52, 7486-7495. DOI:10.1016/j.electacta.2006.12.086

11. S. Martinez, L. Valek, I. Stipanović Oslaković, Journal of The Electrochem. Soc. 2007, 154 (11), C671-C677.

DOI: $10.1149 / 1.2777882$

12. P. E. Laibinis, G. M. Whitesides, J. Am. Chem. Soc. 1992, 114
(6), 1990-1995. DOI:10.1021/ja00032a009

13. Ž. Petrović, M. Metikoš-Huković, R. Babić, Prog. Org. Coat. 2008, 61, 1-6. DOI:10.1016/j.porgcoat.2007.08.006

14. J. C. Love, L. A. Estroff, J. K. Kriebel, R. G. Nuzzo, G. M. Whitesides, Chem. Rev. 2005, 105, 1103-1169.

DOI:10.1021/cr0300789

15. S. Casalini, C. A. Bortolotti, F. Leonardi, F. Biscarini, Chem. Soc. Rev. 2017, 46, 40-71. DOI:10.1039/C6CS00509H

16. S. P. Pujari, L. Scheres, A. T. M. Marcelis, H. Zuilhof, Angew. Chem., Int. Ed. 2014, 53, 6322-6336.

DOI:10.1002/anie.201306709

17. T. Ishizaki, K. Teshima, Y. Masuda, M. Sakamoto, J. Colloid Interface Sci. 2011, 360, 280-288.

DOI:10.1016/j.jcis.2011.04.039

18. T. Ishizaki, M. Okido, Y. Masuda, N. Saito, M. Sakamoto, Langmuir 2011, 27, 6009-6017. DOI:10.1021/la200122x

19. Z. Grubač, M. Metikoš-Huković, R. Babić, I. Škugor Rončević, M. Petravić, R. Peter, Mater. Sci. Eng. 2013, C 33, $2152-$ 2158.

20. A. Raman, M. Dubey, I. Gouzman, E. S. Gawal, Langmuir 2006, 22, 6469-6472. DOI:10.1021/la060636p

21. I. Langmuir, J. Am. Chem. Soc. 1917, 39, 1848-1906. DOI: $10.1021 /$ ja02254a006

22. E. L. Hanson, J. Schwartz, B. Nickel, N. Koch, M. F. Danisman, J. Am. Chem. Soc. 2003, 125, 16074-16080. DOI: $10.1021 / \mathrm{ja} 035956 \mathrm{z}$

23. http://www.scribner.com/products (accessed on 23 March 2018)

24. G. L. Gaines, Insoluble Monolayers at Liquid-Gas Interfaces, New York (John Wiley \& Sons Inc), 1966.

25. E. S. Gawalt, M. J. Avaltroni, N. Koch, J. Schwartz, Langmuir 2001, 17, 5736-5738. DOI:10.1021/la010649x

26. E. S. Gawalt, M. J. Avaltroni, M. P. Danahy, B. M. Silverman, E. L. Hanson, K. S Midwood, J. E. Schwarzbauer, J. Schwartz, Langmuir 2003, 19, 200-204. DOI:10.1021/la0203436

27. M. Metikoš-Huković, R. Babić, I. Škugor Rončević, Z. Grubač, ECS Trans. 2012, 41, 81-91.

28. J. R. Macdonald, Impedance Spectroscopy: Emphasizing Solid Materials and Systems, New York (John Wiley \& Sons Inc), 1987, pp. 301.

29. Z. Lukasc, J. Electroanal. Chem. 1999, 464, 68-75. DOI:10.1016/S0022-0728(98)00471-9

30. J. R. Macdonald, J. Electroanal. Chem. 1994, 378, 17-29. DOI:10.1016/0022-0728(94)87053-5

31. G. Song, A. Atrens, M. Dargusch, Corros. Sci. 1998, 41, 249273. DOI:10.1016/S0010-938X(98)00121-8

32. G. Song, A. Atrens, Adv. Eng. Mater. 2003, 5, 837-858. DOI:10.1002/adem.200310405

33. N. Pebere, C. Riera, F. Dabosi, Electrochim. Acta 1990, 35, 555-561. DOI:10.1016/0013-4686(90)87043-2

34. Y. Jang, B. Collins, J. Sankar, Y. Yun, Acta Biomater. 2013, 9, 8761-8770. DOI:10.1016/j.actbio.2013.03.026

35. R. G. Pearson, Inorg. Chem. 1988, 27, 734-740. DOI:10.1021/ic00277a030

36. R. G. Pearson, J. Chem. Sci. 2005, 117, 369-377. DOI:10.1007/BF02708340 
37. F. H. Walters, J. Chem. Educ. 1991, 68, 29-31. DOI:10.1021/ed068p29

38. G. Klopman, J. Am. Chem. Soc. 1968, 90, 223-234. DOI:10.1021/ja01004a002

39. T. A. Koopmans, Physica 1933, 1, 104-113. DOI:10.1016/S0031-8914(34)90011-2

40. G. Gece, Corros. Sci. 2008, 50, 2981-2992. DOI:10.1016/j.corsci.2008.08.043

41. A. Y. Musa, A. A. H. Kadhum, A. B. Mohamad, A. A. B. Rahoma, H, Mesmari, J. Mol. Struct. 2010, 969, 233-237. DOI:10.1016/j.molstruc.2010.02.051

42. M. Behpour, S. M. Ghoreishi, M. Khayatkashani, N. Soltani, Mater. Chem. and Phys. 2012, 131, 621-633.

DOI:10.1016/j.matchemphys.2011.10.027

43. L. Herrag, B. Hammouti, S. Elkadiri, A. Aouniti, C. Jama, H. Vezin, F. Bentiss, Corros. Sci. 2010, 52, 3042-3051.

DOI:10.1016/j.corsci.2010.05.024
44. M. D. Porter, T. B. Briht, D. L. Allara, C. E. D. Chidsey, J. Am. Chem. Soc. 1987, 109, 3559-3568.

DOI:10.1021/ja00246a011

45. M. A. Szymański, M. J. Gillan, Surf. Sci. 1996, 367, 135-148. DOI:10.1016/S0039-6028(96)00870-9

46. A. Raman, E. Gawalt, Langmuir 2007, 23, 2284-2288. DOI:10.1021/la063089g

47. I. Škugor Rončević, M. Buzuk, N. Vladislavić, Metals 2016, $6316,1-16$.

48. G. Fonder, I. Minet, C. Volcke, S. Devillers, J. Delhalle, Z. Mekhalif, Appl. Surf. Sci. 2011, 257, 6300-6307.

DOI:10.1016/j.apsusc.2011.02.071

49. P. B. Paramonov, S. A. Paniagua, P. J. Hotchkiss, S. C. Jones, N. R. Armstrong, S. R. Marder, J-L. Brédas, Chem. Mater. 2008, 20, 5131-5133. DOI:10.1021/cm8014622

\begin{abstract}
$\mathrm{V}$ tem prispevku smo materiale na osnovi magnezija (Mg in Mg-zlitina (AZ91D)) površinsko modificirali z uporabo različnih organskih kislin (karboksilnih in fosfonskih), da bi izboljšali protikorozijsko zaščito in povečali njihovo biokompatibilnost. Površinski sloj smo vezali $\mathrm{z}$ metodo agregacije in rasti (tethering by aggregation and growth (T-BAG). Razporeditev in način vezave teh plasti smo preučili z infrardečo spektroskopijo (FTIR). Poleg tega smo $s$ semiempiričnimi kvantnokemijskimi metodami poskusili pridobiti boljši vpogled v njihove strukturne in elektronske lastnosti ter preučili korozijsko odpornost v fiziološki raztopini. Korozijsko odpornost modificiranih materialov smo raziskali z elektrokemijsko impedančno spektroskopijo (EIS) v fiziološki raztopini. Rezultati modifikacije magnezija in materialov na osnovi magnezija $\mathrm{z}$ nanosom strukturno urejenih monoplasti organskih kislin (self-assembled monolayer $(\mathrm{SAM}))$ kažejo na izboljšanje korozijskih lastnosti teh materialov. Najboljšo protikorozijsko zaščito ( 87 \% za magnezij in 93 \% za Mg zlitino (AZ91D) dosežemo z uporabo oktadecilfosfonske kisline (ODPA).
\end{abstract}

